\title{
“COM FA FAENA DE FUSTA". EL RETABLO RENACENTISTA DEL GREMIO DE CARPINTEROS DE VALENCIA*
}

\author{
Carlos Enrique Navarro-Rico ${ }^{1}$ \\ Universitat de València
}

El gremio de carpinteros de Valencia costeó un nuevo retablo a partir de 1542, que fue realizado por el escultor Damià Gonçalbes. Sus pinturas fueron contratadas con Onofre Falcó, y los temas representados constituyen un discurso autorreferencial que justifica visualmente el viraje en el patronazgo corporativo y dignifica el oficio al vincularlo a san José y otros santos.

Palabras clave: Onofre Falcó; Damià Gonçalbes; Joan de Joanes; carpinteros; retablo; san José; Valencia.

\section{“COM FA FAENA DE FUSTA". THE RENAISSANCE ALTARPIECE OF THE CARPENTERS GUILD OF VALENCIA}

Around 1542, the Valencia Carpenter's Guild commissioned a new altarpiece, which was made by the sculptor Damià Gonçalbes. Onofre Falcó was hired to undertake its painting, and the requested subjects constitute a self-referential discourse that dignifies carpentry through links between the profession, its patron saint, Joseph, and other saints.

Key words: Onofre Falcó; Damià Gonçalbes; Joan de Joanes; carpenters; altarpiece; Saint Joseph; Valencia.

Cómo citar este artículo / Citation: Navarro-Rico, Carlos Enrique (2021) “'Com fa faena de fusta'. El retablo renacentista del gremio de carpinteros de Valencia”. En: Archivo Español de Arte, vol. 94, núm. 376, Madrid, pp. 335-350. https://doi.org/10.3989/aearte.2021.19

El oficio de la carpintería es uno de los mejor conocidos de la historia de la artesanía y la construcción en la ciudad de Valencia. ${ }^{2}$ Si en 1290 recibía el privilegio real que le permitía instituir una cofradía de carácter asistencial en el convento de san Francisco, no fue hasta 1387 que comenzaron a introducirse en ella ordenanzas de cariz profesional, económico y corporativo. También a finales del trescientos los carpinteros adquirieron una capilla en la iglesia de san Juan del Mercado o de los santos Juanes, consagrada al culto de su nuevo patrón, san Lucas, ${ }^{3}$ y que en lo sucesivo se convertiría en uno de los principales espacios de representación de la identidad colectiva. En ella

\footnotetext{
* Trabajo enmarcado en el proyecto I+D del Ministerio de Economía, Industria y Competitividad, HAR201783070-P, Geografias de la movilidad artística: Valencia en Época Moderna. Su realización fue posible gracias a la financiación de la Generalitat Valenciana y el Fondo Social Europeo a través de una beca predoctoral, bajo la dirección de la Dra. Yolanda Gil Saura.

${ }_{1}$ carlos.e.navarro@uv.es / ORCID iD: https://orcid.org/0000-0002-9080-4357

2 Tramoyeres, 1889. Villalmanzo, 1990. Izquierdo, 2011a. Martínez Vinat, 2018: 478-491. Como señala este último (pp. 60-73), el término "gremio" resulta anacrónico para referirnos a las cofradías de oficio, aunque en nuestro texto los utilicemos como términos sinónimos.

${ }^{3}$ Martínez Vinat, 2018: 481-482.
} 

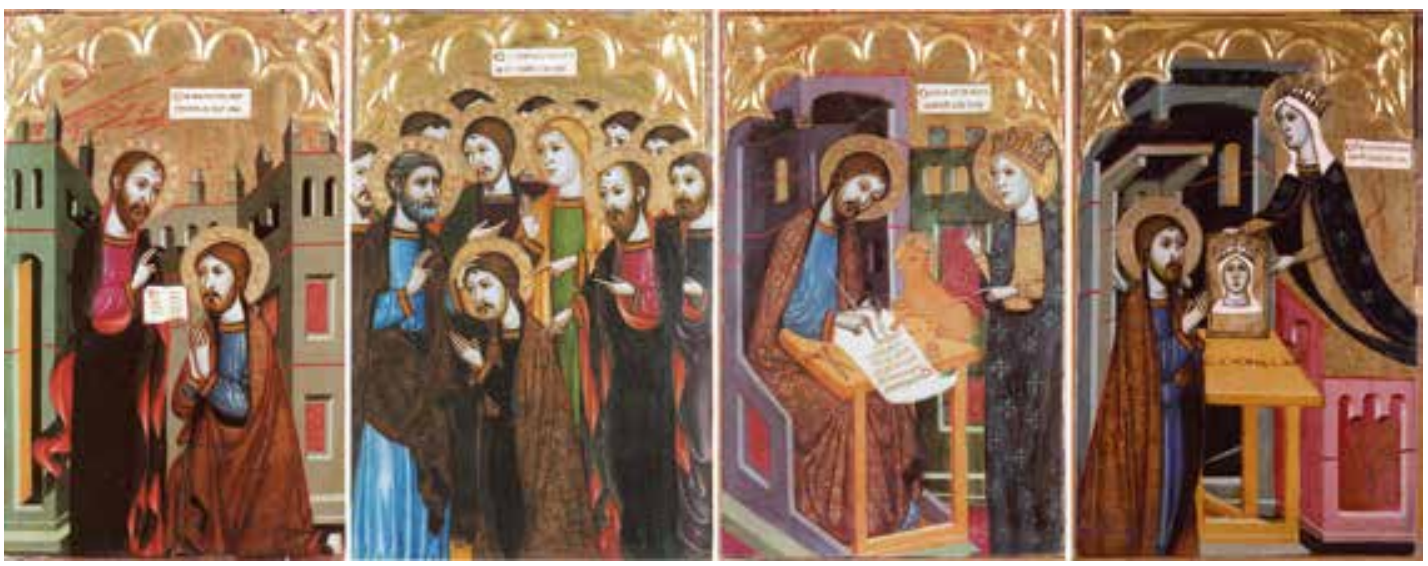

Fig. 1. Llorenç Saragossà, escenas de la vida de san Lucas. (C) Museu de Belles Arts de València.

dispusieron un retablo cuyas tablas conservadas se han atribuido a Llorenç Saragossà (doc. 13631406) [fig. 1], ${ }^{4}$ y desplegaron un importante patrimonio mueble y litúrgico, en el que las armas del oficio - un hacha y una sierra - campaban por doquier. ${ }^{5}$

Estas son todavía visibles en el dintel de la puerta de la casa que la cofradía adquirió en 1479, junto al convento de la Encarnación. Su emplazamiento era idóneo, pues se encontraba en un espacio urbano habitado mayoritariamente por "fusters", muy cercano a la predicha iglesia de san Juan, pero adscrito a la gran parroquia de san Martín. ${ }^{6}$ A partir de entonces la casa, que contaba con huerto, almacén y también capilla, se erigió en sede de la corporación, asumiendo una importante función asociativa y representativa. ${ }^{7}$ En ella tenían lugar sus asambleas o "capítulos", tanto los generales como los que reunían a los encargados de su gobierno, que recaía en una junta de prohombres - "pro[ho]menia"- renovada anualmente el 18 de octubre, festividad de san Lucas. A la cabeza se hallaba el clavario, asistido por un "companyo", por algunos "majorals" y otros cargos, y a manera de secretario actuaba el "escrivà" o escribano, que tomaba nota en los llamados "libros de clavería" de las cuentas y acuerdos. ${ }^{8}$ En ellos se incluía, por supuesto, la renovación de elementos de importancia, como podían ser los retablos corporativos, y en este artículo presentamos las noticias documentales sobre uno de ellos, dedicado a san Lucas y también a san José, cuya mazonería se comenzó en 1542, y que en 1545 quedaba en manos del pintor Onofre Falcó para su dorado y policromado.

\section{Las capillas del oficio de carpinteros}

El 12 de mayo de 1542, el clavario Miquel Roselló pagaba por algunos trabajos que se habían realizado en el huerto de la casa del oficio, así como por el encalado aplicado a la capilla de la parroquia de san Juan; ${ }^{9}$ parece pues que en aquel momento se realizaban tareas de remozo de ambos

${ }^{4}$ Pitarch, 1981: 115. Según Villalmanzo, 1990: 38, este retablo fue sustituido en 1473.

${ }^{5}$ Izquierdo, 2011a: 356-359. García Marsilla, 2011: 633-634.

${ }^{6}$ Gran parte de los carpinteros eran feligreses de esta parroquia, y la cofradía celebraba en ella oficios y ofrendas. Por ejemplo, en 1542 pagaba "all vigari de Sent Marti" por "lles ofertes de lles mises de lla gonfraria g'es diuen tots diumenges e festes manades". Arxiu del Regne de València (ARV), Gremis, lib. 182, f. Xv ${ }^{\circ}$.

${ }^{7}$ Sobre este espacio urbano - la "fusteria"—y la adquisición de la casa: Izquierdo, 2011a: 345-377.

${ }^{8}$ Izquierdo, 2011a: 213-214.

9 'Divendres, a XII de ma[i]g, donà per donar lla letada a lla gapella de sent Johan, e fer un peus en la paret de ll'ort [de la casa], per miga garegua de galls e miga dotsena d'arena, e mans dell mestre e manobres en alltres misèries ge s'[h] an despés... lliures XV sous I [diner]”. ARV, Gremis, lib. 182, f. XIvo. 
espacios. ${ }^{10}$ Esto es importante, puesto que los diferentes indicios sobre el retablo que nos ocupa no aclaran a cuál de las dos capillas estaba destinado, si a la parroquial, o a la de la casa.

La primera se hallaba en un populoso templo, donde estaría plenamente justificada la innovación en la imagen que el oficio pretendía transmitir a sus conciudadanos. ${ }^{11}$ Pero las noticias del periodo que nos atañe y que se refieren de manera evidente a esta capilla - "lla gapella de sent Johan"- se reducen al encalado señalado, así como a la adquisición de algunos aderezos. ${ }^{12}$ Tan solo vuelve a mencionarse de forma explícita en dos notas de 1553: en mayo y junio se registraron sendos pagos "per enlumenar lo retaule de la capella de sent Johan"; sumaban la ajustada cantidad de 62 sueldos - poco más de tres libras-, y además incluían los gastos de un andamio y unas escaleras. ${ }^{13}$ Visto esto, sería lógico pensar que se trataría de pagos residuales por el conjunto pictórico encargado a Falcó y, sobre todo, por su instalación en la capilla de la iglesia.

No obstante, no es tan sencillo. Los apuntes sobre el retablo no mencionan expresamente la capilla de la parroquia, sino a "la cofradía", expresión ambivalente que en la documentación refiere tanto a la institución como a su propia sede. También en 1542 los carpinteros habían decidido celebrar la fiesta de uno de sus patrones, san José, en la propia casa y no en el convento de la Encarnación, como era costumbre, ${ }^{14} \mathrm{y}$ aunque esta fuese una decisión puntual, quizá puso sobre la mesa la necesidad de completar la capilla privada con un retablo, motivando su hechura. Además, en junio de 1545, poco después de acordarse el policromado con Falcó, adquirían materiales para "el capítol" - la sala de reunión-, y aprovechaban para adquirir una viga para la grada "de lla capella de la confraria", lo cual parece aludir al entarimado del altar. ${ }^{15}$ Cierto es que las anotaciones adolecen de un carácter ambiguo y parcial, pero en febrero de 1548 se había pagado por "bajar el pie del altar, y poner el retablo en la capilla del capítulo", ${ }^{16} \mathrm{y}$ esta nota no ofrece lugar a dudas sobre el espacio al que remite. Además, un par de meses después se encargó el tallado de unas claves de bóveda, que se dicen destinadas "a la capela"; mientras que el pago de una lámpara, inmediatamente posterior, sí se especifica destinado "a la capela de sent Luch, a sent Johan" ${ }^{17}$ Ahondando en la posibilidad de que el nuevo retablo se dispusiera en la capilla privada de la cofradía, sabemos que en ella se encontraba, en 1569, un "altar [...] bien adereshado", "so ynbocación de san Jusephe y san Lucas". ${ }^{18}$ Ahora bien, esta descripción no tiene por qué estar refiriéndose a un retablo como tal, pues en un inventario de la casa de 1556 aparece mencionada "una ymage de Nostra Senyora ab sent Josef y sent Luch", ${ }_{19}$ que junto con otras imágenes y elementos litúrgicos bien podrían estar conformando dicho altar.

10 Todavía en 1549 seguían los trabajos en la casa. ARV, Gremis, lib. 188, f. 63.

${ }^{11}$ Sobre la expresión de la identidad y el orgullo corporativos: Izquierdo, 2011 b.

12 Un guadamecí "per a ll'alltar de lla gapella de sent Luch", en 1543. ARV, Gremis, lib. 184, f. X. Unos corporales "per a la gapella de sent Johan", en 1546, y 1547 "un faristol de pintar per a sent Johan a lla gapella". ARV, Gremis, lib. 187, f. VI-VIIvo. En 1548 se realizaba una de las muchas lámparas que iluminaban la capilla. ARV, Gremis, lib. 188, f. 56. En julio de 1550 se compró un portapaz de madera para la capilla de la parroquia. ARV, Gremis, lib. 190, f. 58v.

13 "A XXIIII de mag, donà a un enlumenador de retaules, per enlumenar lo retaule de la capella de sent Johan, singuanta i dos sous, ab despeses de la bastida e pots de unes esgalles... II lliures XII sous.

Més a II de guny, donà a l'enlumenador, per enlumenar lo retaule de la Verge Maria i sent Luch i sent Gosep... lliures X sous". ARV, Gremis, lib. 143, f. 45.

${ }^{14}$ ARV, Gremis, lib. 182, f. 23. Es curioso que la fiesta — que constaba de oficio religioso y banquete — no se celebrara el día del santo, si no en una jornada estival: en 1542 se celebró el 13 de agosto (ARV, Gremis, lib. 182, f. XVv'), en 1543 el 27 del mismo mes (ARV, Gremis, lib. 182, f. VIIIIv'), pero en 1552 tuvo lugar el 6 de junio (ARV, Gremis, lib. 192, f. 61).

15 "E més, per al capítol, una [...] g'està entorn del capítol, e una biga per al graó de lla capella de la confraria, dotse sous, dich... lliures XII sous". ARV, Gremis, lib. 185, f. VIv".

16 "Més doní a dos [...] y a l'andador, per a devalar lo peu de l'altar y posar lo retaule en la capela del capítol... lliures I sou VI [diners]". ARV, Gremis, lib. 188, f. 57.

17 "Més a VI de abril, donà a hu[n] entalador per fer huna senta Bàrbera en huna clau de la capela, sis sous... VI sous [...] Més per huna trosada de quartó per a la glau de la capela, y per los glaus per a glavar-la... lliures sous VIIII [diners]. Més per huna làntia per a la gapela de sent Luch, a sent Johan... lliures sous X [diners]". ARV, Gremis, lib. 188, f. 58.

${ }_{18}$ ARV, Gremis, c. 657, n. 1198.

${ }^{19}$ ARV, Gremis, lib. 196, f. 74. 
Así las cosas, no podemos asegurar en cuál de las dos capillas se dispuso el nuevo retablo. Puede que se llevara a la capilla privada, quizá más necesitada de un altar de estas características, y que sería el descrito en 1569; en este caso, esos pagos de 1553 "per enlumenar lo retaule" de la capilla de la iglesia harían referencia al remiendo del antiguo conjunto. Pero dado que estos señalan "lo retaule de la Verge Maria i sent Luch i sent Gosep", también podemos pensar que refieren al nuevo, y que este se instaló en la capilla parroquial, siendo el antiguo el que se trasladó a la sede confraternal. En cualquier caso, la documentación que traemos a colación demuestra que el gremio emprendió la construcción de un nuevo retablo corporativo, contando para ello con artistas tan destacados como Damià Gonçalbes y Onofre Falcó.

\section{El nuevo retablo y su programa iconográfico}

El día 25 de mayo del reiterado 1542, el escribano del oficio de los carpinteros anotaba que el clavario le había pagado treinta sueldos, a cuenta de la madera que había tomado de Joan Gregori, ${ }^{20}$ "per all retaule". ${ }^{21}$ En aquel momento el escribano era Damià Gonçalbes, conocido como Damià Carles ${ }^{22}$ quien probablemente habría "tomado" la madera para ocuparse él mismo de la obra. El 8 de agosto ya se había trasladado la mazonería a la casa de la cofradía, ${ }^{23}$ aunque aún el 9 de septiembre se registraba un pago, algo confuso, a cuenta de más madera por otros treinta sueldos, pagándose también el torneado de las columnas, que costó diez sueldos, y todo sumado a la entrega de mayo hacía un total de tres libras y media. ${ }^{24} \mathrm{Al}$ final de aquel libro de clavería se encuentra un breve memorial en el que se recoge la madera "que he puesto" en el retablo; ${ }^{25}$ la primera persona nos hace reafirmar que sería Gonçalbes el encargado de su realización.

No hay más noticias al respecto hasta que el 4 de enero de 1545, los carpinteros decidían encargar su policromado, y para sufragarlo, algunos cofrades ofrecieron donativos, que quedaron anotados en dos listados, de los que el primero refiere "las promesas hechas" y "las limosnas". En él se inscriben diferentes maestros, algunos de los cuales muestran una cruz frente al nombre, que podría indicar que abonaron lo prometido. Hallamos a escultores como Luis Muñoz II, discípulo de Forment e hijo de un célebre artífice homónimo; ${ }^{26}$ o Pere Dorpa, imaginero flamenco llegado a Valencia en el círculo de Mencía de Mendoza. ${ }^{27}$ También este listado contiene, sin ninguna cruz, el compromiso de Joan Gust, indicándose "que [h] de pagar [seis sueldos] a Visent Johan, de pintar"; volveremos sobre este apunte al final de nuestro texto. En cuanto al segundo listado, enumeraba los nombres de los obreros u oficiales que también hicieron donativos para "lo pintar del retaule". ${ }^{28}$ La determinación no se dilató en el tiempo, y el 25 de enero acordaban con Onofre Falcó que doraría el retablo y pintaría sus tablas por el precio total de treinta y cinco ducados, que

${ }^{20}$ Este carpintero, además de trabajar en obras muy destacadas de su momento, fue también un importante proveedor de madera. Gómez-Ferrer, 1998: 326-327; 2019.

21 'Divendres, a XXV de ma[i]g, donà a ll'esgriva trenta sous, per lla fusta qe prengué de mestre Gargori, per all retaulle de lla gonfraria... I lliura X sous". ARV, Gremis, lib. 182, f. XIv".

${ }^{22}$ ARV, Gremis, lib. 182, f. XXXVII.

23 “Dimarts, a VIII d'agost, [h]a pagat per gavar l'ort gatre sous e tres diners... lliures IIII sous III [diners].

Per portar lo retaule a lla gonfraria... lliures I sou". ARV, Gremis, lib. 182, f. XIIv".

24 "Disabte, a VIIII de setenbre, donà a lla fusta del retaule gom aga pugat tres lliures e miga, e dells trenta sous estaria asentats e[n] alltra par[t], e deu sous per tornegar les golunes dell retaule, tot tres liures e miga... II lliures". ARV, Gremis, lib. 182, f. XIIv .

25 "Que e posat". ARV, Gremis, lib. 182, f. 31v.

${ }^{26}$ Sobre él, Gómez-Ferrer, 1998: 334. La relación con Forment la descubrió Abizanda, 1915: 97-98. La retoma Morte, 2009: 216.

${ }^{27}$ Gómez-Ferrer, 2009.

28 ARV, Gremis, lib. 185, f. LVII-LVIIII. 


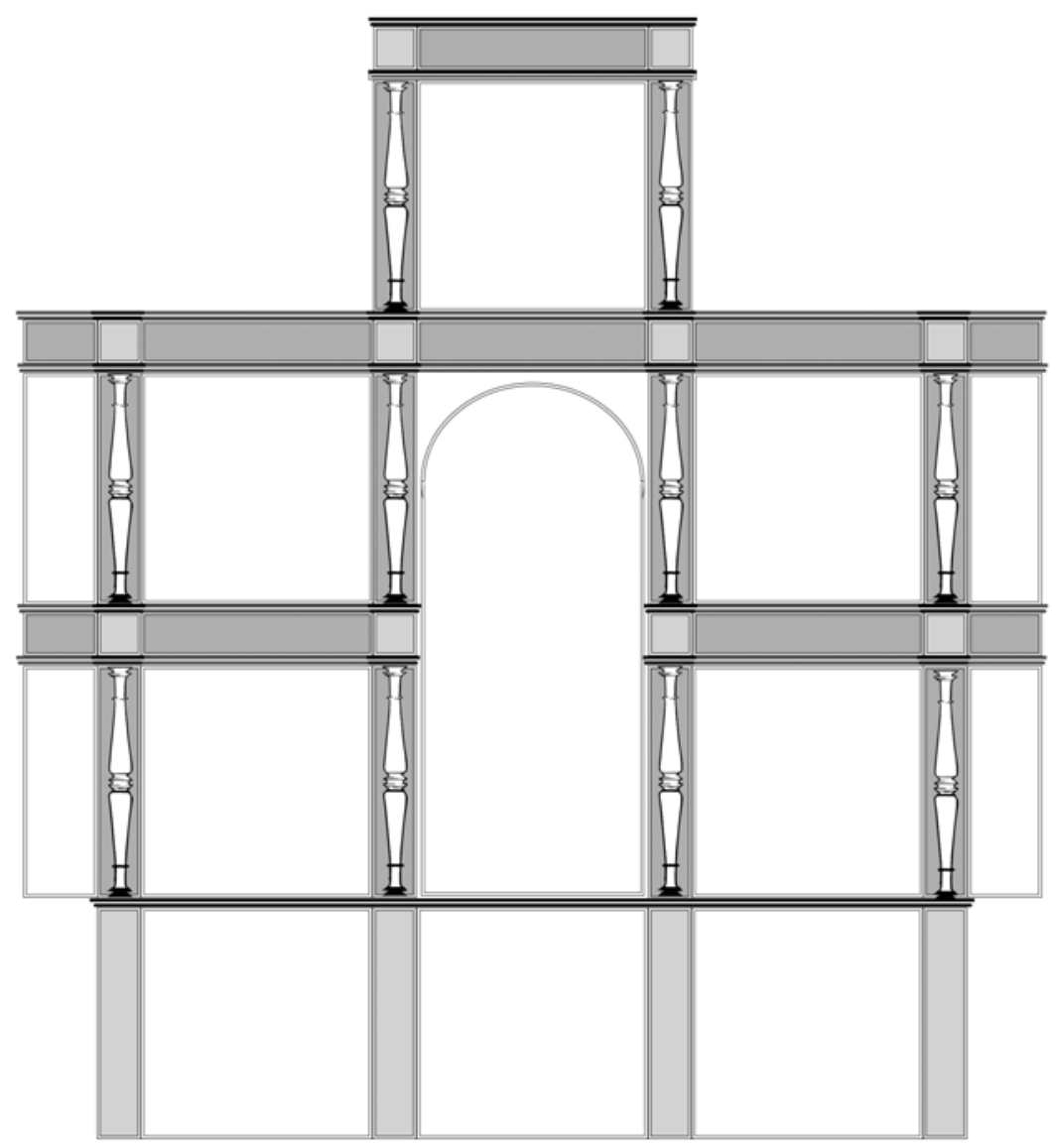

Fig. 2. Reconstrucción hipotética del retablo de los carpinteros.

en moneda valenciana equivalían a treinta y seis libras y diez sueldos. ${ }^{29}$ Entre el 12 de febrero y el 15 de marzo se trasladó la estructura de madera a casa del pintor. ${ }^{30}$

Gracias al compromiso con Falcó, podemos reconstruir su aspecto [fig. 2]. Se trataba de un altar con un banco de tres casillas, un cuerpo principal de tres calles con guardapolvos - estos tan solo laterales-, y un ático. Sabemos que contaba con soportes exentos, pues se trabajó en su torneado, pero en nuestra opinión, más que como columnas propiamente dichas - "colunes"-, deben interpretarse como fustes abalaustrados, una opción muy en boga en aquel momento, dada la influencia de tratados como el Medidas del Romano (1526) de Sagredo, donde aparecen descritos como columnas "monstuosas". Los hallamos también en otras obras entalladas por Gonçalbes, que mencionamos más adelante, así como en la sillería de la Capilla Real del convento de santo Domingo, ejecutada por el predicho Joan Gregori con diseños de Onofre Falcó, hacia 1536; o en la galería superior de la Sala Nova de la Generalitat, comenzada en 1540, y cuyo progreso el propio Gonçalbes examinó y tasó en 1543, junto a Luis Muñoz II. ${ }^{31}$

En cuanto a los temas e imágenes del retablo, se le solicitaban al artista dos "estories" de la vida de san José: una que mostrase sus desposorios con la Virgen, destinada a la "espiga" o ático; y otra en la que se le mostrase trabajando la madera, acompañado y ayudado por el Niño Jesús, que se dispondría en el centro del banco. A ambos lados de esta se instalarían dos tablas dedicadas

${ }^{29}$ ARV, Gremis, lib. 185, f. XXXXIIIvo . Véase anexo documental.

30 "Més lo dia ge portaren lo retaule a gasa'l pintor, donà divut diners a [...] Giner... lliures I sou VI [diners]". ARV, Gremis, lib. 185, f. Vv .

${ }^{31}$ Aldana, 1992: 238-239. 
a san Lucas, pero sin detallarse los episodios requeridos. Para los lados del nicho central se mencionan cuatro santos, que podían aparecer emparejados o pintados de manera individual —opción por la que nos decantamos-, de modo que en las calles laterales quedarían encasillados unos encima de otros. Los elegidos fueron los dos santos Juanes, y san Gil y "sent Jaume" — es decir, Santiago, sin especificarse cuál de ellos-. Por último, se mencionan en el texto los "guardapolvos de [los] lados", lo cual indica que este fue uno de los primeros retablos en los que desaparecían las polseras de la cornisa superior y el ático, en una solución que tendría mucha fortuna en la retablística de la segunda mitad de la centuria. Como es lógico, el número de pinturas incluidas en estos laterales habría de ser par; no obstante, en el acuerdo se mencionan solo tres: san Jerónimo, san Vicente Ferrer y san Sebastián. Suponemos que la que no se nombra pudo mostrar al otro patrón valenciano, san Vicente mártir; o a san Roque, habitualmente representado junto a san Sebastián; sea como fuere, esta omisión pudo deberse a un probable despiste a la hora de anotar el acuerdo.

Hay aspectos del contenido iconográfico de este conjunto que merecen reflexión. Así, si los santos escogidos para los guardapolvos eran representados de manera muy frecuente, los que se hallaban en las calles laterales plantean alguna cuestión interesante. La presencia de los santos Juanes responde a motivos obvios, dada su popularidad y la vinculación del oficio con su parroquia, pero la de san Gil y Santiago resulta un poco más singular. Conviene recordar que en el convento del Carmen se encontraba un retablo dedicado a san Gil y Santiago el Mayor, en cuya tabla central (Museo de Bellas Artes de Valencia) aparecían emparejados, ${ }^{32}$ de modo que existía un referente iconográfico que quizá deseaban rememorar. Del primer santo, legendario eremita y abad, existía cierta tradición devocional en la ciudad; ${ }^{33}$ sin embargo, en cuanto al segundo, pudo haber otros condicionantes que motivaran su inclusión, pero escogiendo, en lugar de a Santiago el Mayor, al Menor. Este último ya tenía, en una de las tablas del primitivo retablo de Saragossà, un papel destacado, ${ }^{34}$ con lo que su figura sería conocida entre los carpinteros, y pudo tener más relevancia de la que creíamos, como comentaremos enseguida.

En cuanto al protagonismo del retablo, y como no podía ser de otro modo, lo ostentaban los dos patrones del oficio, san Lucas y san José, asociado este a la Virgen y al Niño Jesús. La documentación no revela a cuál de los dos representaba la imagen que ocuparía la hornacina central, o si aparecían emparejados - lo cual tampoco sería extraño-, pero la importancia concedida al santo patriarca en el programa iconográfico, en detrimento de la que había tenido el evangelista anteriormente, responde a diversas circunstancias devocionales e históricas que merece la pena retomar.

Como dijimos, al establecerse en su capilla de san Juan del Mercado a finales del siglo XIV, los carpinteros habían consagrado su patronazgo y el de la corporación a san Lucas, al que se hacía médico y, sobre todo, pintor. Tradicionalmente se ha aducido que esta elección pudo derivar de la influencia de los pintores, a los que se suponía colegiados en la agrupación, dado que el soporte de su obra era mayoritariamente la madera. ${ }^{35}$ Cierto es que entre sus filas se englobaban, en principio, todos los artesanos que la utilizaban como materia prima para desarrollar su trabajo, lo cual implicaba una enorme diversidad de oficios. En las ordenanzas de 1482 aparecen citadas todas aquellas especialidades, empezando por "los carpinteros y pintores cajeros, así pintores de cofres como de cajas, arquibancos moriscos, cubiertas de casas, paveses [...], banderas y otras señas [...]" ${ }^{36}$ Parece que estos maestros que entallaban y, sobre todo, policromaban cajas, cofres y escudos, estaban de algún modo a la cabeza de la corporación, y el caso del linaje Girbés, aunque excepcional, puede servir para poner de relieve esta situación y la variedad de labores que asumían. Dedicados desde principios del siglo XV a los encargos reales, ${ }^{37}$ fue Martí Girbés —agremiado entre los

\footnotetext{
32 Atribuida hoy a Joan Reixach (n. ${ }^{\circ}$ inv. 174).

33 Contaba con una capilla en la catedral desde 1388. Sanchis Sivera, 1909: 335 . El convento de san Agustín conservaba una reliquia suya. Jordán, 1712: 57.

${ }^{34}$ Izquierdo, 2011a: 360-361.

${ }^{35}$ Villalmanzo, 1990: 37-38. Sobre el ejercicio de la pintura a finales del XIV y principios del XV: Miquel / Serra, 2011.

36 Villalmanzo, 1990: 22, 160-161.

${ }^{37}$ Un remoto Martí Girbés fue nombrado por Fernando I (1380-1416) pintor de la ciudad, y hacia 1424 Joan Girbés realizó una serie de cajas por encargo real. Véase Miquel, 2011: 61.
} 
“fusters"38 — quien policromó y doró en 1498 las bóvedas del salón columnario de la Lonja. Que su hijo Gaspar se mencionase como "mercader" al recibir los cuantiosos pagos debidos a su padre por aquel trabajo, ${ }^{39}$ podría ser una prueba de la prosperidad que se granjearon, abandonando así el artesanado.

No obstante, entre los pintores vinculados a la primitiva cofradía no parecen hallarse documentados los que consideraríamos hoy artistas, es decir, los que pintaban retablos; y la distancia entre estos y los cajeros quedó tajantemente establecida en aquel 1482, cuando a los pintores retablistas o figurativos se les reconoció ajenos a la entidad, con el objetivo de excluirles del lucrativo negocio de las cajas ornadas. ${ }^{40}$

En el retablo hecho por Saragossà a finales del XIV [fig. 1] se representa a san Lucas recibiendo de la Virgen, en una de las tablas, las indicaciones para redactar el Evangelio, mientras que en otra le entrega ella misma su propio retrato o vera effigies. El asunto es de sobra conocido, y sus implicaciones metapictóricas han sido objeto de destacados estudios; ${ }^{41}$ por ello, solo incidiremos aquí en el valor que tendría para los artesanos — más bien para los cajeros - reflejar en la actividad del santo la suya propia, aunque en un plano abstracto. No perdamos de vista que los temas pintados serían escogidos por aquellos, y que habría un pretendido interés en identificarse con la figura de su patrón.

Además de las tablas que se conservan de este primitivo conjunto pictórico, debió haber alguna más, en la cual quizá se explicitase de algún modo la vinculación con la carpintería, pero el culto a san José fue poco popular durante el medievo, de modo que su presencia, si es que la tuvo, no sería importante. Sin embargo, ya hemos apuntado que, en la tabla que muestra la incorporación de san Lucas al colegio apostólico, aparece destacado Santiago el Menor, y esto puede no ser gratuito ni casual. A lo largo de los siglos se produjeron confusiones en los atributos de algunos apóstoles cuya hagiografía era menos conocida o estaba menos canonizada, y ello derivó, por ejemplo, en la asignación al Menor de una sierra o una escuadra, lo cual llevó a asociarle con el oficio de carpintero. ${ }^{42}$ Es posible que el gremio quisiera dar cabida en su retablo a este santo para redundar en este juego de identificaciones, concediendo espacio a la actividad que caracterizaba a la mayoría de sus miembros.

Unos años después de excluir a los pintores figurativos, el gremio reconocía en 1497 que su "propria invocació" era la de san José, pero que su festividad no se observaba como era debido, pues al parecer algunos trabajaban en dicha jornada, lo cual decidían sancionar, ${ }^{43}$ aun con todo, todavía en 1552 tenía que advertirse a los cofrades de "que no se hiciera trabajo" el 19 de marzo. ${ }^{44}$ Fue a partir de estos años centrales del quinientos en que comenzó a solemnizarse la festividad del santo patriarca, aunque lo cierto es que la celebración más señalada para los carpinteros siguió siendo durante mucho tiempo la de san Lucas - 18 de octubre $-{ }^{45}$ En realidad, este proceso fue paralelo a la reconsideración que a lo largo del XVI se fue haciendo de san José a nivel litúrgico y devocional, popularizándose su culto gracias a diferentes textos y a la influencia de santa Teresa de Ávila y la orden carmelita; no por casualidad, junto a la casa de los carpinteros se encontraba el convento de monjas carmelitas de la Encarnación, y como dijimos, en él celebraban estos artesanos la fiesta del santo. ${ }^{46}$

${ }^{38}$ Fue clavario en el curso 1481-1482. ARV, Gremis, lib. 230. Sus noticias se extienden hasta 1502. Miquel, 2011: 61 (nota 66).

39 Aldana, 1982: 7-9.

40 Izquierdo, 2011a: 241-242.

${ }^{41}$ Portús, 2016: 42-54.

42 Uscatescu, 2013.

${ }^{43}$ Villalmanzo, 1990: 38-39.

${ }^{44}$ ARV, Gremis, lib. 192, f. 60.

${ }^{45}$ Villalmanzo, 1990: 37-39. Izquierdo, 2011a: 385-392. En 1543 se destinaron a la fiesta de san José menos de seis libras y media, mientras que la de san Lucas costó más de doce. ARV, Gremis, lib. 183, f. VIIIIv $-\mathrm{X}$.

46 Véase nota 14. 


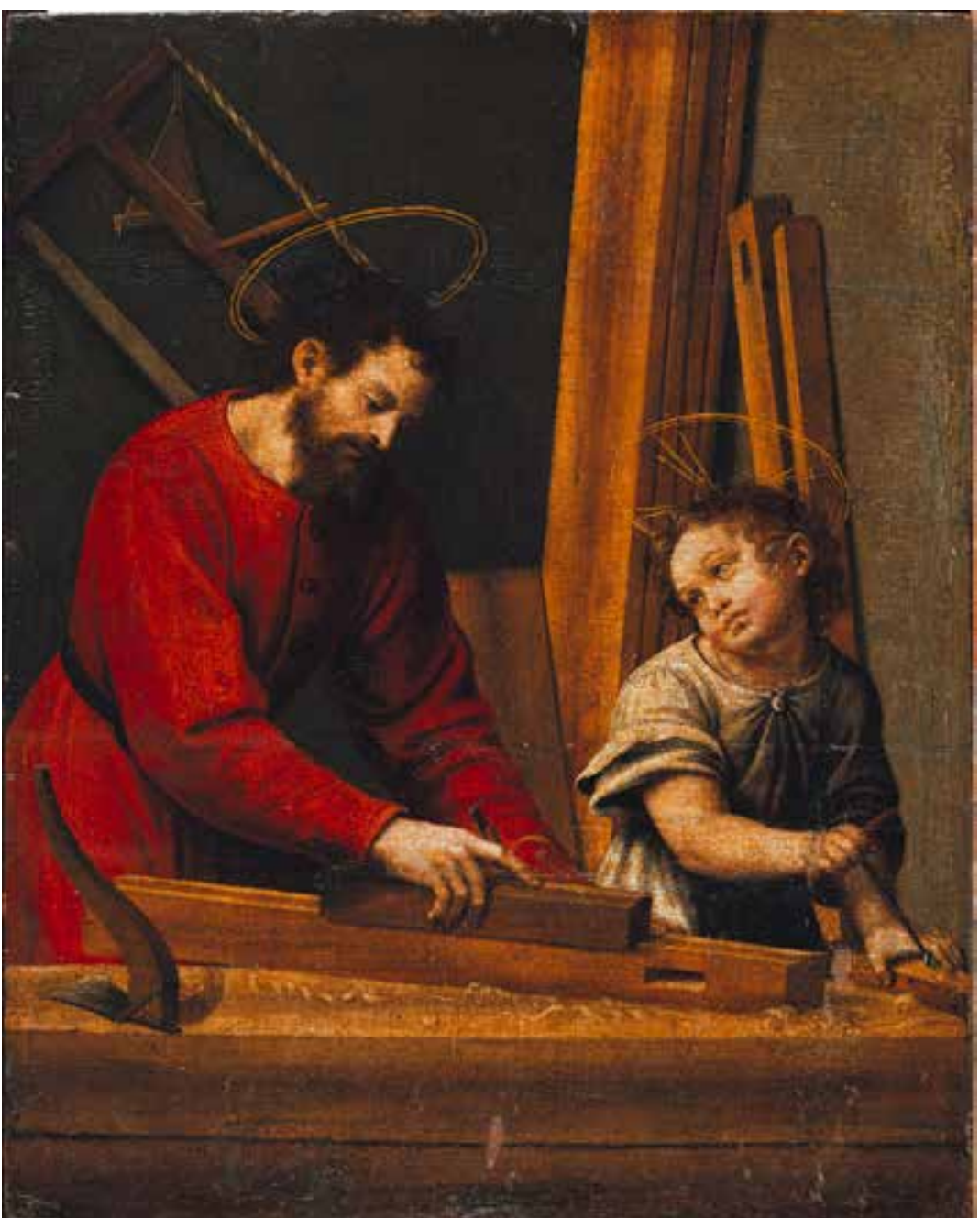

Fig. 3. Joan Vicent Macip, alias Joan de Joanes. San José y el niño Jesús en el taller del carpintero, (C) Staatliche Museen zu Berlin, Gemäldegalerie / Jörg P. Anders.

Todo ello tuvo su consecuencia visual en el retablo encargado a Falcó, pues las dos tablas dedicadas a san Lucas quedaban relegadas a los espacios laterales del banco, mientras que las de san José ocupaban los lugares más notorios, al disponerse en el ático y entre las dos del evangelista. Además, se especificaban los temas, ambos procedentes de los relatos apócrifos. La primera escena, la de los Desposorios, resaltaba la virtud y la estrecha relación con la divinidad de san José, al mostrar el momento en que se convertía en el esposo de María, elegida por Dios para engendrar a su Hijo. Pero la segunda era una escena doméstica, en la que se mostraba al patriarca "com fa faena de fusta en ll'infant Jesús", es decir, faenando con la ayuda del Niño. Esto resultaba de una gran originalidad, por el carácter cotidiano o "de género" que ya Benito percibió en una pequeña pintura contemporánea y del mismo tema, atribuida a Joanes, que se conserva en la Gemäldegalerie de Berlín [fig. 3], y de la cual podrían derivar otras versiones que incluían a la Virgen. ${ }^{47}$ De hecho, podemos proponer que la presente en el retablo que nos ocupa pudo tomar una composición similar, o que incluso fue la que inauguró en Valencia esta interpretación concreta del tipo iconográfico, de enorme éxito posterior ${ }^{48}$ En cualquier caso,

47 Benito, 2000: 86-87.

${ }^{48}$ El documento presenta, al describir esta escena, una anotación al margen que ofrece dificultades en su lectura, y que podría leerse como "madona", en referencia a la Virgen. 


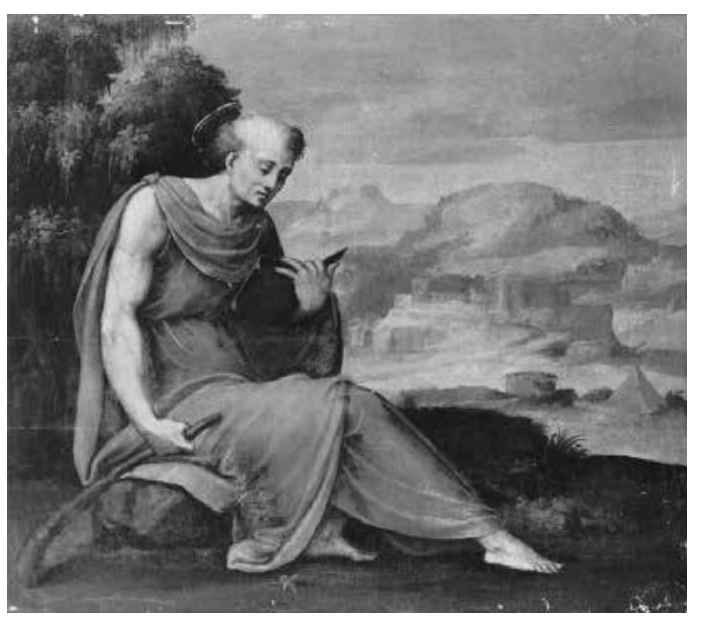

Fig. 4. Onofre Falcó (atrib.), Santiago el Menor (?). Archivo Moreno, IPCE, Ministerio de Cultura.

resaltaba el carácter humilde y trabajador del santo, ${ }^{49}$ y lo igualaba a los fieles y especialmente a los carpinteros, que se identificaban con él y sentían dignificados tanto su ocupación como su transmisión generacional, ${ }^{50} \mathrm{de}$ modo que esta nueva imagen contribuiría a la consolidación de su patronazgo y de su devoción entre estos artesanos.

Desgraciadamente no conocemos nada más sobre las tablas contratadas por Falcó, y si fueron destruidas o permanecen sin localizar o identificar. En este sentido, la labor que se está realizando en la atribución al pintor de nuevas obras sienta las bases para posibles respuestas futuras. Gómez Frechina le ha asignado una representación de un apóstol, seguramente Santiago el Menor, que se encontraba en la colección Argudín y conocemos por una fotografía [fig. 4]. ${ }^{51}$ Esta puede ofrecer pistas acerca del aspecto que ofrecería el "sant Jaume" del retablo del gremio, en tanto que no era uno de los apóstoles más comúnmente figurados, identificado gracias a la porra que empuña, en referencia al madero con que fue golpeado por un batanero, según una versión de su martirio. ${ }^{52}$ Del mismo modo, dicho investigador aporta también antiguas fotografías de sendas pinturas que se encontraban en la colección Navarro, y que en un mismo formato muestran a san Juan Bautista y a un "santo obispo" en un agreste paisaje,,$^{53}$ identificado como prelado por la mitra y la capa pluvial que viste y el báculo que sostiene. Planteamos la posibilidad de que se trate no de un obispo, sino de san Gil, que por su condición de abad se reviste a veces con las prendas litúrgicas mencionadas, y a cuyos inicios eremíticos haría referencia el entorno. Desde luego, sería atractivo sugerir la identificación de estas tablas atribuidas con las que hemos documentado aquí, pero sin duda ello requiere una demostración más sólida que de momento no es posible afrontar.

\section{La obra en el contexto de la producción de Gonçalbes y Falcó}

En los últimos tiempos se han realizado interesantes aportaciones sobre los artistas que operaron en el panorama renacentista valenciano, entre los que se encuentran tanto Damià Gonçalbes como Onofre Falcó. Ambos se vienen perfilando como figuras muy destacadas de aquel momento, por el reconocimiento y el lugar que ocuparon entre sus contemporáneos, y el encargo inédito de los carpinteros y sus circunstancias vienen a reforzar esta posición; por ello, este merece ser encuadrado en sus biografías y su producción.

La de Gonçalbes es una personalidad aún algo difusa. Desde su primera semblanza, ${ }^{54}$ han ido apareciendo de forma fragmentaria nuevos datos, que le vinculan con los más reconocidos pintores y escultores del momento. Aclarando algunas confusiones y sumando alguna noticia

49 Sobre la representación y la iconografía de san José: Civil, 2005. Una aproximación a a los talleres valencianos del medievo a través de las representaciones de san José y la Sagrada Familia, en Izquierdo, 2017.

${ }^{50}$ En la raíz de este reconocimiento con san José se hallan el desarrollo de la identidad colectiva y de cierta conciencia de clase entre los carpinteros, así como la recuperación de la "humilde circunstancia del Hijo de Dios", nociones detectadas por Izquierdo, 2011b: 279.

${ }^{51}$ Gómez Frechina, 2018: 194.

52 Uscatescu, 2013: 874.

53 Gómez Frechina, 2018: 196-197.

54 Gómez-Ferrer, 1998: 324-325. 
inédita, podemos trazar un perfil más certero de su figura. Además, recientemente se han producido importantes hallazgos sobre su padre, Carles Gonçalbes, ${ }^{55}$ al que siguió en el oficio de escultor y retablista, y que amplían lo que sobre su formación más temprana podíamos suponer.

En este sentido, hasta ahora había pasado inadvertida su participación, junto a aquel, en el tallado de las primeras puertas del retablo mayor de la catedral valenciana, diseñadas por Hernando Yáñez de la Almedina y Hernando de los Llanos, autores de su célebre ciclo pictórico. ${ }^{56}$ Su estructura se comenzó en septiembre de 1506, y en ellas se trabajó hasta que se dejaron listas para probarse, en febrero de 1507. Después, Damià siguió afanado en la cuadrilla comandada por su padre en la Seo, ocupada en diversas tareas, hasta abril de aquel año. ${ }^{57}$ A partir de entonces debió emplearse en el taller familiar, colaborando en las obras contratadas por su progenitor: en 1505 el gremio de armeros le había encargado que ampliase el programa escultórico de su retablo, iniciado unos años antes; ${ }^{58}$ y también asumiría el del gremio de obrers de vila. ${ }^{59}$

Damià reaparece en las obras de la caja del órgano de la catedral, diseñado también por Yáñez de la Almedina, ${ }^{60}$ a las que se incorporó el 9 de marzo de 1513, al mismo tiempo que el escultor Jaume Vicent, ${ }^{61}$ y en ellas coincidió con otros muchos escultores que hacían "obra de talla". ${ }^{62}$ Vicent dejó esta tarea tras un mes y medio y, pasados unos meses, a finales de agosto, Gonçalbes asumió el mismo jornal que aquel, más elevado que el del resto de tallistas, lo cual significaría que tomaba el mando o una labor más destacada, por un tiempo de seis meses. Esta noticia inédita debe hacer que nos replanteemos la relevancia de Luis Muñoz I — quien se viene considerando el director de esta obra $^{63}$ - Vicent y ahora de Gonçalbes en el conjunto del órgano, y nos habla también de sus elevadas capacidades, pues sin ser maestro todavía ${ }^{64}$ fue el mejor pagado de todos los artífices que allí confluyeron, solo por detrás de Muñoz.

Unos meses después, el 16 de mayo de 1514, se examinó en el gremio de los carpinteros como "entallador", entregando una cruz de nogal para su chapado en plata; quedaría entonces al frente del taller familiar, heredando incluso el nombre del padre como sobrenombre, pues el acta del examen le refiere como "Damià Garlles, allias Garlles". ${ }^{65}$ De hecho, en los documentos de la cofradía no aparece nunca como Gonçalbes, y en ellos le vemos actuando de forma casi constante como escribano ${ }^{66}$ Con todo, el mismo nombre se documenta hasta 1575 , cuando es elegido consejero, ${ }^{67}$ esto se debe a que Damià tuvo un hijo homónimo, que siguió vinculado de forma estrecha al gobierno del gremio, y que es el que llega hasta esta fecha tan tardía.

${ }^{55}$ Gómez-Ferrer, 2016; 2020. En el segundo de estos se demuestra el parentesco entre Carles y Damià.

56 Sobre este: Benito, 1998: 66-117.

57 En estos trabajos aparece como Damià Gosalbes. Arxiu Catedral de València (ACV), Llibres d'obra, sig. 1486 (1506), f. 53-67v.

${ }^{58}$ Gómez Ferrer, 2016.

${ }_{59}$ Gómez-Ferrer, 2020. Se aporta en este artículo la noticia del testamento de Carles Gonçalbes, dictado en mayo de 1508 , y es probable que falleciera poco después.

${ }^{60}$ Advirtió su presencia Gómez-Ferrer, 1998: 324-325. El primer estudio sobre este conjunto, donde no se menciona aún a Gonçalbes, en Gavara / Gómez-Ferrer, 1998.

${ }^{61}$ Sobre este escultor: Iborra, 2019.

${ }^{62}$ En estos trabajos aparece citado como Damià Carles o Damià a secas, pero en el resumen de las cantidades recibidas a final de abril de 1514, se le menciona como Damià Gosalbes, lo cual confirma la identificación. ACV, Llibres d'obra, sig. 1487 (1512), f. 65 y ss.; sig. 1487 (1513), f. 36 y ss.

${ }^{63}$ Luis Muñoz I, padre del Luis Muñoz II ya mencionado, fue un destacado y versátil maestro, que estuvo implicado en obras de gran relieve, tanto como escultor como picapedrero o incluso proyectista. Sobre él: Gómez-Ferrer, 1998: 196-201; 2014: 177-178.

${ }^{64}$ En alguna ocasión se le ha creído maestro ya entonces, pues el 19 de marzo de 1513 aparece mencionado en las cuentas como "mestre de talla". Se trata de un error del fabriquero, pues ni en el resumen de los cobros ni en ninguna otra jornada recibe tal apelativo, sino el de "obrer de talla". ACV, Llibres d'obra, sig. 1487 (1512), f. 66-67.

${ }_{65}^{65}$ ARV, Gremis, lib. 230. El dato se extrae de una cuartilla redactada posteriormente.

${ }^{66}$ Por ejemplo, ya lo había sido en el ejercicio 1539-1540. ARV, Gremis, lib. 180, f. XXXVIIII.

${ }^{67}$ ARV, Gremis, lib. 212, f. 4. 
Damià Carles o Gonçalbes fue un artista versátil, digno heredero del buen nombre del obrador paterno, y a la vez muy atento a las novedades que se iban produciendo. Se entiende así que, en diciembre de 1514, poco después de obtener la maestría, contratara el retablo de la capilla del Rosario del convento de santo Domingo, trazado 'a la romana' y con un gran despliegue escultórico — cuyo policromado fue asumido por Onofre Falcó tiempo después ${ }^{68}$-; y que justo un año más tarde, conviniera la conclusión del retablo de la iglesia de Bocairent (Valencia), junto a los pintores Cabanes y Nicolau Falcó, ${ }^{69}$ siguiendo una obra y modelos de carácter goticista.

Gonçalbes trabajó de nuevo para la catedral en $1533,{ }^{70}$ y en aquel año su hijo cobraba por las "manibus et laboribus" puestas por ambos en el retablo de la Virgen de la Fe y algunas obras del monasterio de la Zaidía. ${ }^{71}$ Entre 1534 y 1536 renovaron juntos algunos elementos del retablo del gremio de los plateros de la iglesia de santa Catalina, dedicado a san Eloy, preparándolo para ser dorado y policromado por parte de Vicent y Joan Macip, alias Joan de Joanes. Se ocuparon de elaborar un nuevo banco o reparar el existente, y lo mismo hicieron con algunos balaustres — "balaguorts"72 - Y en octubre de 1536, Damià otorgaba un ápoca por un retablo que estaba haciendo, siguiendo una manda testamentaria, noticia que le conecta de nuevo con la familia Macip. $^{73}$

Desconocemos cuándo se produjo la muerte de Gonçalbes y el relevo de su hijo al frente del taller, de modo que no sabemos exactamente cuál de los dos fue el que ejerció como clavario del gremio en $1550-1551,{ }^{74} \mathrm{o}$ el que en 1559 entregó, como multa por no acudir al primer capítulo de aquel curso, "huna gubia", ${ }^{75}$ instrumento básico para el ejercicio de la escultura. En cualquier caso, y como hemos visto, este entallador y escultor trabajó vinculado a otros importantes artistas, como los pintores mencionados, y entre sus propios colegas también ocupó un papel destacado, consolidado por su protagonismo en la vida cotidiana del gremio de carpinteros. Así, no es de extrañar que, en 1542, siendo escribano, fuera el encargado de tallar los elementos del nuevo retablo del oficio, que probablemente también diseñó él mismo.

Sobre Onofre Falcó, en los últimos años se han producido grandes avances en su conocimiento, al delimitarse su identidad biográfica y profundizarse en el conocimiento de su estilo y obra, lo cual ha permitido aproximaciones a su catalogación y realizar nuevas atribuciones, como las señaladas más arriba o de tablas aparecidas en el mercado del arte. ${ }^{76}$ Gracias a ello, hoy podemos considerarle uno de los pilares del Renacimiento pictórico valenciano. Hijo de Nicolau Falcó (act. 1493-1530), también desarrolló su formación al amparo del taller paterno. ${ }^{77}$ Su primera referencia documental le vincula a la comitencia aristocrática y se remonta a marzo de 1536, cuando cobró por el trazado de dos diseños para la sillería o bancada que ensamblaron Joan y Gaspar Gregori en la Capilla Real del

\footnotetext{
${ }^{68}$ Martínez Rondán, 1998: 109-110. Gómez-Ferrer, 2017: 134.

${ }^{69}$ Cerveró, 1971: 27.

70 "Item, pose en data que, ha XX de maig, paguí a mestre Damià Carles, fuster, quinze sols, per obrar quatre columnes de fusta per a la custòdia (...) XV sous". ACV, Llibres d'obra, sig. 1489 (1533), s.f.

${ }^{71}$ Gómez-Ferrer, 2016: 285 (nota 52).

72 Puig / Company / Tolosa, 2015: 195-196, asocian estas noticias con Carles Gonçalbez al mencionarse a Damià como "mestre Carles", y además sostienen que realizó un nuevo retablo, lo cual no compartimos porque los apuntes refieren pagos muy ajustados — apenas unas 15 o 16 libras - por "adobar lo retaule".

${ }^{73}$ La pagadora fue Isabel Anna Macip, hermana de Joan de Joanes, que daba así cumplimiento a las voluntades de Caterina Sentgenís. Puig / Company / Tolosa, 2015: 41.

${ }^{74}$ ARV, Gremis, lib. 191, f. 2v.

${ }_{75}$ ARV, Gremis, lib. 198, f. 110v.

${ }^{76}$ El Museo de Bellas Artes de Valencia ha incorporado de forma reciente a su colección una tabla de la "Oración en el huerto", que Gómez Frechina atribuye a Falcó. Gómez Frechina, 2020: 32-33.

77 Según Hernández / Gómez, 2018: 41, el retablo de las Almas de Torrent habría sido realizado hacia 1530 en el taller paterno, pero ya bajo la dirección de Onofre. Es en este estudio en el que los autores abordan dicha catalogación.
} 
convento de santo Domingo, bajo patronato de Mencía de Mendoza. ${ }^{78}$ En noviembre estuvo implicado en la contratación, por parte del escultor Joan de Salas, del retablo de la Virgen de las Fiebres de la iglesia de san Martín. En febrero de 1538 asumía el dorado y el policromado del retablo de la capilla del Rosario del convento de santo Domingo ${ }^{79}$ realizado más de veinte años antes por Gonçalbes, y que estaba bajo el patrocinio de la importante familia de los Sorell. También en este año está fechado el retablo de la Sangre de Estivella; ${ }^{80}$ y entre 1539 y 1540 hizo pequeños trabajos para el Hospital General. ${ }^{81}$ En 1542 se le documenta como "retabulorum pictorum", ${ }^{82}$ y contaba con un significativo taller, pues fue uno de los pintores que pagaron un impuesto más alto — diez sueldos — en la tacha real de aquel año, junto a otros como Joan de Joanes; cantidad que ascendió en 1547 hasta los dieciocho sueldos, siendo el que asumió el mayor gravamen. ${ }^{83}$

Es, por tanto, en esta situación de pujanza del obrador de Falcó, en la que se enmarca el encargo de los carpinteros. No parece que estos acudieran a la reunión del 4 de enero con un artista escogido, y probablemente se valoraron varios artífices; incluso podría plantearse que fueron Gonçalbes o Joan Gregori - con cierta relevancia aquel día ${ }^{84}$ - los que propusieron a Falcó, pues ambos le conocían de forma cercana, al haber coincidido en diversas obras. Pero llegados a este punto, queremos reparar en la ya referida "promesa" que hizo Joan Gust, y que especificaba que "a de pagar a Visent Johan, de pintar". El apunte no resulta claro, pero podría identificarse, a manera de hipótesis, al mencionado con Vicent Joan Macip, Joan de Joanes. La idea no es absurda en tanto que Joanes era otro de los pintores más importantes de la ciudad, habiendo realizado de forma reciente el conjunto pictórico del retablo de san Eloy, del gremio de plateros (1534-1538), ${ }^{85}$ remendado para ello por Gonçalbes. Es posible que en aquel momento se barajase su nombre, pero otros trabajos le llevasen a declinar el encargo. Sabemos que en 1539 había contratado el retablo de la Preciosísima Sangre de Cristo, del Hospital de la Reina, que habría de entregar en el transcurso de seis años. ${ }^{86}$ Además, en septiembre de 1542 se comprometía con la cofradía de la Trinidad y san Miguel, de la iglesia de san Nicolás, a realizar uno de sus retablos, y a este pudo seguir un segundo. ${ }^{87}$

La posible coincidencia entre Falcó y Joanes en este proceso podría llevarnos a ampliar la hipótesis al punto de que, al no asumir Joanes el trabajo, fueron su voluntad e indicaciones las que lo llevaron a las manos de Falcó. Al respecto, se ha señalado que entre ambos pudo existir cierta colaboración, a raíz de la documentación del retablo de la parroquia de san Bartolomé, pues Falcó preparaba, en 1552, las tablas que habría de pintar después Joanes ${ }^{88}$ una relación que podría ser anterior en el tiempo, dado que el conjunto se venía realizando desde $1537 .{ }^{89}$ Asimismo, no podemos dejar de mencionar el famoso retablo de la parroquia de san Esteban, sobre el cual el canónigo Vitoria dejó escrito que, habiéndose celebrado un concurso entre Falcó y Joanes para ver quién lo asumiría, y aun demostrando el primero una gran habilidad, fue ganado por el segundo, que "era mayor águila". ${ }^{90}$ La narración, aun con su carácter novelesco, fue determinante para identificar a Falcó como autor de las tablas del conjunto que no podían adscribirse a Joanes. Últimamente se

${ }^{78}$ Gómez-Ferrer, 2011-2012: 87-88.

${ }^{79}$ Martínez Rondán, 1998: 106-110.

${ }^{80}$ Gómez Frechina, 2009: 368.

${ }^{81}$ Gómez Ferrer, 1998: 344.

82 Gómez-Ferrer, 2011-2012: 95 (nota 50).

83 Falomir, 1994: 99.

${ }^{84}$ Joan Gregori fue designado aquel día "clavari dels dos diners", quedando encargado de custodiar algunos recursos económicos.

${ }^{85}$ Benito / Vallés, 1991: 353-356.

86 Gómez-Ferrer / Corbalán, 2012.

${ }^{87}$ Puig / Company / Tolosa, 2015: 113-116.

${ }_{88}$ González Martí, 1928: 126-127.

${ }^{89}$ Benito / Vallés, 1991: 356-358. Puig / Company / Tolosa, 2015: 109-111.

${ }^{90}$ Bassegoda, 1995: 168. 

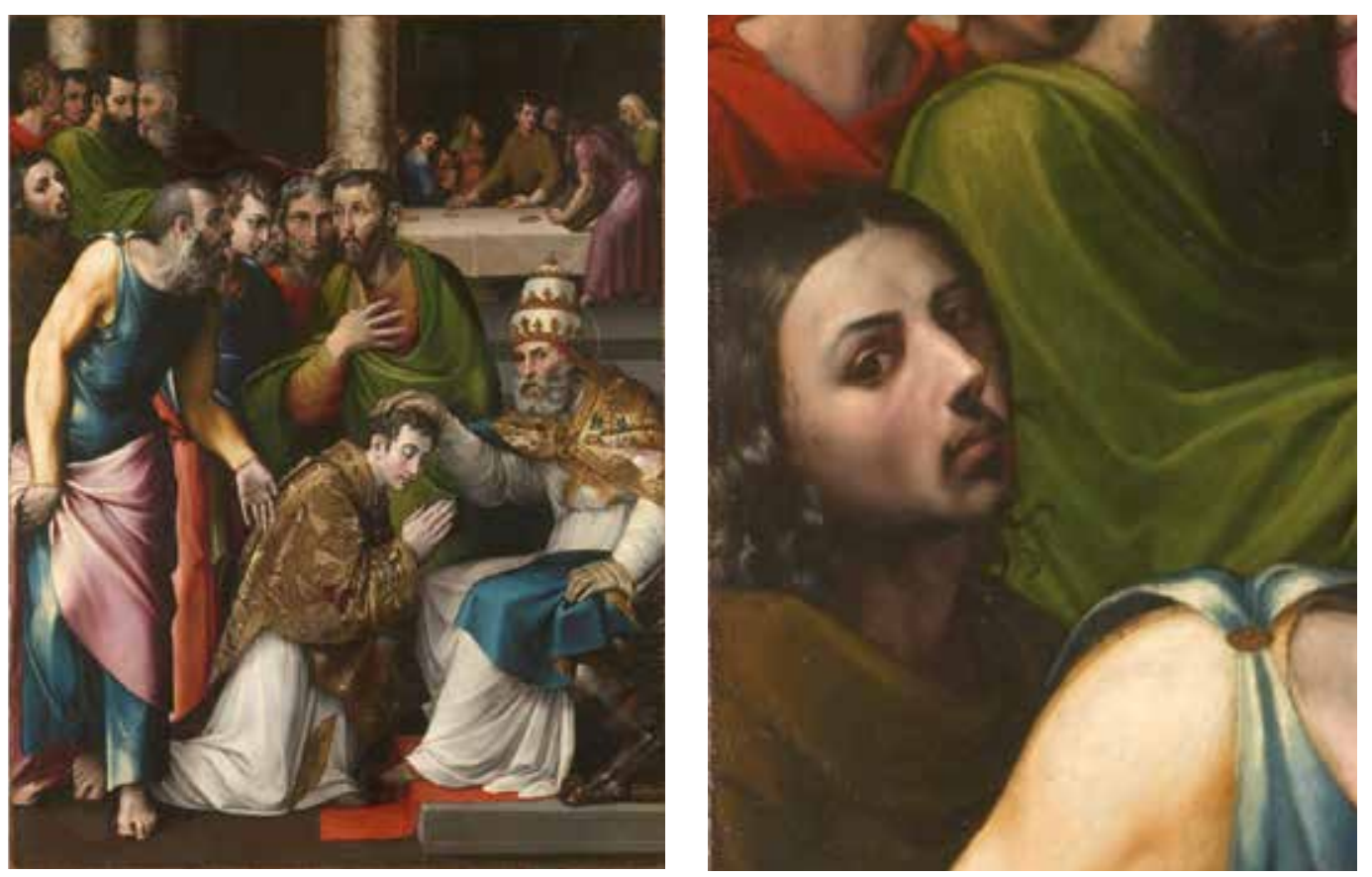

Fig. 5. Onofre Falcó, Ordenación de san Esteban (y detalle). (C) Museo del Prado.

ha ofrecido una solución muy lógica para esta historia, que desmentiría esa supuesta victoria o la superioridad de Joanes, al sugerirse que Falcó inició el conjunto, auspiciado por su amigo, el influyente Joan Aguiló y Romeu de Codinats, baile de Valencia en 1556 y uno de los promotores de la obra. Falcó realizó tres tablas, entre ellas la "Ordenación de san Esteban" — en la cual pudo autorretratarse [fig. 5] ${ }^{91}$ - ; y tras su muerte, acaecida en 1560, Joanes habría continuado el ciclo, cobrando en 1562 la "Lapidación de san Esteban". 92

Volviendo al conjunto de los carpinteros, y aun planteándose la hipótesis de la posible implicación de Joanes partiendo del apunte descrito, debemos remarcar que Falcó no dependería de su tutela para la consecución de este o cualquier otro encargo, pues tenía cierta cultura, como hemos visto contó con insignes amigos y comitentes, y regentaba un taller competente y acreditado, no necesariamente percibido como inferior al de Vicent Joan Macip por sus contemporáneos. No por casualidad, alcanzó en 1556 el puesto de pintor de la Generalitat. ${ }^{93}$

\section{Conclusión}

En definitiva, podemos concluir que el gremio de carpinteros de la ciudad de Valencia encomendó al escultor Damià Gonçalbes, en 1542, la construcción de un nuevo retablo, cuyo dorado y policromado fue confiado a Onofre Falcó en 1545, aunque se plantee la hipótesis de que se valorase la posibilidad de contar con Joan de Joanes para ello. A falta de indicios más concluyentes, no podemos precisar a cuál de las dos capillas del oficio estaba destinado este nuevo

${ }^{91}$ El autorretrato fue identificado por Benito, 1986, aun creyendo que el autor era Vicente Requena.

92 Gómez-Ferrer, 2011-2012: 89-90. Fueron aportaciones importantes sobre este retablo las de Gómez-Ferrer, 1995. González García, 1999. Un último estado de la cuestión en Puig / Company / Tolosa, 2015: 120-125.

${ }_{93}$ Gómez-Ferrer, 2011-2012: 90. 
conjunto. Pero su hechura, su diseño y los temas solicitados revelan que la corporación reaccionó de forma muy atenta a los cambios sociales, artísticos y devocionales del momento, así como a sus propias necesidades identitarias, renovando su imagen corporativa y consolidando la figura de san José como patrón del gremio, en detrimento de la de san Lucas. Además, la noticia del retablo y sus circunstancias amplían lo conocido sobre sus artífices y sobre el importante papel que jugaron en el panorama artístico de la Valencia del Renacimiento, que aún hoy sigue ofreciendo gratas sorpresas.

\section{Anexo documental}

1545, enero 27. Valencia.

Memoria del acuerdo entre Onofre Falcó y el gremio de carpinteros. ARV, Gremis, lib. 185, f. XXXXIIIv'.

La concordia del retaule feta per llos magorals del pintar de lla confraria.

Diumenge, a XXV de giner, any mil D garanta e sinch: concordaren los magorals e pro[ho]mens ab l'onorat Enofre Falcó de pintar-los lo retaule de la confraria, per preu de trenta e sinch ducats, e dich: XXXVI lliures XV sous; sò és de pintar e daurar, ab dos estòries de sent Josep: la una en la espiga de l'esponsalisi de sent Josep ab la Verge Maria, enmig del banc la'stòria de sent Josep gom fa faena de fusta en ll'infant Jesús a [en el margen izquierdo: madona] engudant [sic: enjudant, ajudant] de fusta; en llos gostats del banch, dos estòries de sent Luch; en los gostats del mig sent Johan Batiste, sent Johan Evangelliste, sent Gaume, sent Gil. Dempré[s] en lles polseres de[ls] costats sent Geroni, sent Visent Ferer, sent Sabastià; colunes, e f[r] isos, e besalts [sic: resalts] e mo[t]llures e defenisions d'or fi. Lo preu ga'stà de dalt mensionat: los trenta e sinch ducats. E per lla memòria asente lo sobredit escriute [sic] en los libres de l'oficy, a XXVII de giner. Yo, Damià Carles, escrivà dels fusters. Sit laus Criste, Amen.

\section{BIBLIOGRAFÍA}

Abizanda, Manuel (1915): Documentos para la historia artística y literaria de Aragón procedentes del archivo de Protocolos de Zaragoza, siglo XVI. Zaragoza: La Editorial.

Aldana, Salvador (1982): "La Lonja de Valencia”. En: Archivo de Arte Valenciano, 63, pp. 3-19.

Aldana, Salvador (1992): El Palacio de la Generalitat de Valencia. Valencia: Consell Valencià de Cultura.

Bassegoda, Bonaventura (1995): "Vicente Vitoria (1650-1709), primer historiador de Joan de Joanes". En: Locus Amoenus, 1, pp. 165-172.

Benito, Fernando (1986): "Vicente Requena «el Viejo», colaborador de Joan de Joanes en las «Tablas de San Esteban» del Museo del Prado". En: Boletín del Museo del Prado, 19, pp. 13-29.

Benito, Fernando (1998): Los Hernandos. Pintores hispanos del entorno de Leonardo. Valencia: Consorci de Museus de la Comunitat Valenciana.

Benito, Fernando (2000): Joan de Joanes. Una nueva visión del artista y su obra. Valencia: Museo de Bellas Artes.

Benito, Fernando / Vallés, Vicente (1991): "Nuevas noticias de Vicente Maçip y Joan de Joanes”. En: Archivo español de arte, 255, pp. 353-361.

Cerveró, Luis (1971): "Pintores valentinos. Su cronología y documentación”. En: Archivo de Arte Valenciano, 42, pp. 23-36.

Civil, Pierre (2005): "El artesano y el artista: aspectos de la iconografía de San José". En: Les Cahiers de Framespa. Noveaux champs de l'histoire sociale, 1. En: <http://journals.openedition.org/framespa/420> [2-12-2020].

Company, Ximo (1991). L'art i els artistes al País Valencià modern (1440-1600). Barcelona: Curial.

Falomir, Miguel (1994): La pintura y los pintores en la Valencia del Renacimiento (1472-1620). Valencia: Consell Valencià de Cultura.

García Marsilla, Juan Vicente (2011): "Bellesa compartida. Confraries, oficis i parròquies com a clients artístics a la València medieval”. En: Afers, 70, pp. 601-634.

Gavara, Joan J. / Gómez-Ferrer, Mercedes (1998): "Fernando Yáñez de la Almedina y el órgano renacentista de la catedral de Valencia”. En: Benito, Fernando (com.). Los Hernandos. Pintores hispanos del entorno de Leonardo. Valencia: Consorci de Museus de la Comunitat Valenciana, pp. 235-246. 
Gómez Frechina, José (2009): "Retablo de la Crucifixión”. En: Garín, Felipe / Pons, Vicente (coms.). La gloria del Barroco. Valencia: Generalitat Valenciana, pp. 368-369.

Gómez Frechina, José (2018): “Onofre Falcó, a Spanish Renaissance master”. En: Colnaghi Studies Journal, 3, pp. 179200.

Gómez Frechina, José (2020): “Onofre Falcó. Oració a l'Hort”. En: Gimilio, David (dir.). Més museu: últimes adquisicions del Museu de Belles Arts de València (2010-2020). Valencia: Generalitat Valenciana, pp. 32-33.

Gómez-Ferrer, Mercedes (1995): "Nuevas noticias sobre el retablo de la vida de San Esteban de Joan de Joanes". En: Boletín del Museo del Prado, 34, pp. 11-14.

Gómez-Ferrer, Mercedes (1998): Arquitectura en la Valencia del siglo XVI. El Hospital General y sus artífices. Valencia: Albatros.

Gómez-Ferrer, Mercedes (2009): "Sobre los inicios del escultor flamenco Pedro Dorpa en Valencia (act. 1545-1586)". En: Boletín de la Sociedad Castellonense de Cultura, 85, pp. 433-440.

Gómez-Ferrer, Mercedes (2011-2012): "Los Falcó, una familia de pintores en la Valencia del siglo XVI". En: Locus Amoenus, 11, pp. 79-96.

Gómez-Ferrer, Mercedes (2014): "Viajes de ida y vuelta. La recepción del Renacimiento en Valencia”. En: Company, Ximo / Franco, Borja / Rega, Iván (eds.). Bramante en Roma, Roma en España. Un juego de espejos en la temprana Edad Moderna. Lleida: Centre d'Art d'Època Moderna, pp. 160-183.

Gómez-Ferrer, Mercedes (2016): "El relieve del Tránsito de la Virgen de la catedral de Valencia, obra de Carles Gonçalbez. A propósito de la escultura valenciana en la transición al siglo XVI”. En: Goya, 357, pp. 271-285.

Gómez-Ferrer, Mercedes (2017): "Miguel del Prado, pintor de retablos en Valencia. Su fallecimiento en las Germanías (1521)". En: Archivo Español de Arte, 358, pp. 125-140.

Gómez-Ferrer, Mercedes (2019): "Unos techos en busca de autor: la familia Gregori y los artesonados del castillo de Alaquàs”. En: Quaderns d'Investigació d'Alaquàs, 39, pp. 127-151.

Gómez-Ferrer, Mercedes (2020): "The Hispanic Society's Resurrection relief, a Valencian work from the turn of the sixteenth century”. En: Sculpture Journal, 29, pp. 159-178.

Gómez-Ferrer, Mercedes / Corbalán, Juan (2012): "Un contrato inédito de Juan de Juanes. El retablo de la cofradía de la Sangre de Cristo de Valencia (1539)". En: Archivo Español de Arte, 337, pp. 1-16.

González García, Juan Luis (1999): ““Ut pictura rhetorica”: Juan de Juanes y el retablo de San Esteban de Valencia”. En: Boletín del Museo del Prado, 35, pp. 21-56.

González Martí, Manuel (1928): Pintors valencians de la Renaixença. Joanes: l'enigma de la seua vida. Valencia: Sociedad Valenciana de Publicaciones.

Hérnandez, Lorenzo / Gómez, Antonio (2018): Biografia y catálogo razonado del pintor valenciano Onofre Falcó. Madrid.

Iborra, Federico (2019): “Jaume Vicent: un escultor singular en la encrucijada de dos siglos". En: Archivo de Arte Valenciano, 100, pp. 43-56.

Izquierdo, Teresa (2011a): El fuster: definició d'un ofici en la València medieval. Tesis doctoral. Valencia: Universitat de València.

Izquierdo, Teresa (2011b): "La imagen como símbolo de identidad corporativa. La cofradía de carpinteros de Valencia: construcción y representación de su imagen como corporación”. Codex Aquilarensis, 27, pp. 277-290.

Izquierdo, Teresa (2017): "Nuevas consideraciones en torno a la iconografía del obrador de san José carpintero. A partir de las evidencias documentales de la carpintería en Valencia entre 1400 y 1530 ”. Revista Digital de Iconografía Medieval, 18, pp. 67-84.

Jordán, Jaime (1712): Historia de la provincia de la corona de Aragón de la sagrada orden de los ermitaños de nuestro gran padre san Augustin (...). Parte primera. Tomo segundo. Valencia: Antonio Bordázar.

Martínez Rondán, Josep (1998): El Retaule de la Resurrecció de la Seu de València. Sagunt: J. Martínez.

Martínez Vinat, Juan (2018): Cofradias y oficios. Entre la acción confraternal y la organización corporativa en la Valencia medieval (1238-1516). Tesis doctoral. Valencia: Universitat de València.

Miquel, Matilde (2011): Retablos, prestigio y dinero: Talleres y mercado de pintura en la Valencia del gótico internacional. Valencia: Universitat de Valencia.

Miquel, Matilde / Serra, Amadeo (2011): ““'Se embellece toda, se pinta con pintura de ángeles”. Circulación de modelos y cultura pictórica en la Valencia de 1400". En: Artigrama, 26, pp. 333-380.

Morte, M. ${ }^{a}$ Carmen (2009): Damián Forment, escultor del Renacimiento. Zaragoza: Caja Inmaculada.

Pitarch, Antonio José (1981): “Llorenç Saragossa y los orígenes de la pintura medieval”. En: D’Art, 6-7, pp. 109-119.

Portús, Javier (2016): Metapintura. Un viaje a la idea del arte en España. Madrid: Museo del Prado.

Puig, Isidro / Company, Ximo / Tolosa, Luisa (2015): El pintor Joan de Joanes y su entorno familiar. Los Macip a través de las fuentes literarias y la documentación de archivo. Lleida: Universitat de Lleida.

Sanchis Sivera, José (1909): La catedral de Valencia: guía histórica y artística. Valencia: Imprenta de Francisco Vives Mora.

Tramoyeres, Luis (1889): Instituciones gremiales. Su origen y organización en Valencia. Valencia: Domenech. 
Uscatescu, Alexandra (2013): “Arte y tecnología textil: el emblema de Santiago el menor (siglos XI-XVI)”. En: Anuario de estudios medievales, 43, pp. 871-914.

Villalmanzo, Jesús (ed.) (1990): Libre de ordenacions de la Almoyna e Confraria del Offiçi dels Fusters. Valencia: Boronat.

Fecha de recepción: 24-V-2021

Fecha de aceptación: 22-VII-2021 